\title{
DO IN-VEHICLE ADVANCE SIGNS BENEFIT OLDER AND YOUNGER DRIVER INTERSECTION PERFORMANCE?
}

\author{
Susan L. Chisholm, Jeff K. Caird, Julie A. Lockhart, Natalie H. Vacha \\ Cognitive Ergonomics Research Laboratory (CERL) \\ University of Calgary \\ Calgary, Alberta, Canada \\ Christopher J. Edwards \\ Virginia Tech Transportation Institute \\ Blacksburg, Virginia, USA
}

\begin{abstract}
Summary: An experimental study was conducted to determine if intersection behavior of those 18 to 24 and $65+$ benefited from advanced in-vehicle signs presented in a head-up display (HUD) format. The University of Calgary Driving Simulator (UCDS) was used to determine whether intersection performance improved in the presence of several advanced signs or whether unwanted adaptive behaviors occurred (e.g., increasing speed to run the light instead of stopping). Invehicle signs facilitated an increase in stopping occurrences for both younger and older drivers at intersections with relatively short yellow onsets. In addition, eye movement analysis revealed significant age effects with regard to vertical and horizontal gaze variablity, with younger drivers showing increases in vertical gaze variability compared to the older drivers. Younger drivers also looked more often and had longer percentage of durations fixating on the HUD compared to the older drivers.
\end{abstract}

\section{INTRODUCTION}

Older drivers are known to have higher crash risks for many intersection manuevers (Preusser et al., 1998). Young drivers on the other hand usually have age-related advantages over older drivers, with faster reaction times, better vision, and superior information processing abilities (Caird et al, 2005; Maltz \& Shinar, 1999). With the increasing aging population, it is important to address the older driver deficits in driving performance to decrease crash risk.

In-vehicle signs have been identified as a beneficial intelligent transportation systems (ITS) technology (Caird, 2004; Hanowski et al., 1999; Nakata et al., 2002; Regan, 2004), but have received only modest research attention. The use of in-vehicle technology to alert drivers to upcoming traffic light changes has the potential to benefit the older driving population. The purpose of this study was to determine if in-vehicle advanced warning signs could improve both younger and older drivers' intersection performance. Two in-vehicle signs advanced warning signs were evaluated in a head-up display (HUD) format to determine if the signs were able to improve intersection stopping performance or if they produced unwanted behavioral side effects (Tufano, 1997). 


\section{METHOD}

\section{Driving Simulator}

The University of Calgary Driving Simulator (UCDS) was integrated by KQ Corporation (now called DriveSafety) and a number of custom modifications to the data acquisition and analysis software were made to it in the Cognitive Ergonomics Research Laboratory (CERL). A more thorough description of the UCDS can be found elsewhere (Caird et al., 2005).

\section{Eye Movement System}

An Applied Sciences Laboratory (ASL) 501 system was used to measure the participants' eye movements. This is achieved through illumination if the eye with a near infrared beam, the reflection of which is captured by a solid-state video sensor. The illumination beam and the image of the eye are reflected via a headband-mounted monocle just below the drivers' left eye. The illuminator, optics, and camera are contained in the Head Mounted Optics Module (HMO) mounted on the participant's head. The Magnetic Head Tracking Hardware (MHT) is mounted in the vehicle near the participants head, and is responsible for determining the position of the head.

Output from the eye, scene camera, and magnetic head tracker is processed through a Model 5000 control unit, and sampled at $60 \mathrm{hz}$. The control unit extracts the pupil and cornea reflection information and computes pupil diameter and line of gaze. Head-tracking information from the MHT is processed through EYEHEAD ${ }^{\mathrm{TM}}$ integration software, which is then combined with the eye position information to determine a participants' point of gaze in the world. Spatial error rate is less than 1 degree between true eye position and computed measurement in the central field of view, but may increase up to 2 degrees for the periphery of the visual field.

Eye tracker data collection and information is submitted to a software package called EYENAL TM. Utilizing specialized functions available in the application, the operator can determine fixation durations, fixation sequences, and Areas of Interest (AOI). Eye movement data are then processed offline.

\section{Participants}

A total of 24 participants, half 18 to $24(M=21.5)$ and half 65 to $76(M=69.2)$, volunteered for the study, with equal numbers of men and women. The decision to select participants from these specific age ranges was based on performance differences from previous studies (Caird \& Chugh, 1997; Wolffsohn, et al., 1998), and the labour intensive constraints of eye movement analysis. Participants were recruited through the local newspaper and renumerated for their time. All participants were screened for simulator sickness, visual acuity, contrast sensitivity, colour deficiency, and mental and physical health. The characteristics of those in this study can be found in Table 1.

\section{Procedures}

All participants drove a 6-minute practice drive to become aquainted with the vehicle. The practice drive included two light changes: one at $2.21 \mathrm{~s}$ and one at $1.73 \mathrm{~s}$ from the intersection 
stop line. The experimental session consisted of four 10-minute drives each consisting of 12 intersections with a posted speed limit of $70 \mathrm{~km} / \mathrm{hr}$. All intersections consisted of 4-lanes, parked cars, oncoming and cross traffic. The first and last drives acted as baseline data collection. The order of drive presentation was counterbalanced.

Table 1. Age group, number of participants per group, mean age, average kilometers driven per year, total number of crashes since licensure, number of moving violations, and visual acuity or minimum angle of resolution (MAR) with correction

\begin{tabular}{|l|l|c|c|c|c|c|}
\hline \multicolumn{1}{|c|}{ Age Group } & \multicolumn{1}{|c|}{$\mathbf{N}$} & $\begin{array}{c}\text { Mean Age } \\
\text { (SD) }\end{array}$ & $\begin{array}{c}\text { Km/ Year } \\
\text { (SD) }\end{array}$ & $\begin{array}{c}\text { Lifetime } \\
\text { Crashes (SD) }\end{array}$ & $\begin{array}{c}\text { Moving } \\
\text { Violations } \\
\text { (SD) }\end{array}$ & $\begin{array}{c}\text { Visual } \\
\text { Acuity } \\
\text { (SD) }\end{array}$ \\
\hline 18-24 years & 12 & $21.5(2.2)$ & $\begin{array}{c}19,167 \\
(13,347)\end{array}$ & $0.6(1.1)$ & $0.9(1.2)$ & $0.88(0.18)$ \\
\hline $65+$ years & 12 & $69.2(3.3)$ & $\begin{array}{c}18,167 \\
(6,658)\end{array}$ & $3.5(2.5)$ & $3.5(2.5)$ & $1.65(0.34)$ \\
\hline $\begin{array}{l}\text { Total/Means } \\
(\mathrm{SD})\end{array}$ & 24 & $46.35(24.53)$ & $\begin{array}{c}18,667 \\
(10,327)\end{array}$ & $2.0(2.4)$ & $2.0(2.1)$ & $1.43(0.47)$ \\
\hline
\end{tabular}

Of the 48 intersections encountered, 24 included signal changes to amber. Half of the changes were $1.73 \mathrm{~s}$ and the other half were $2.21 \mathrm{~s}$ prior to the stop line of the intersection. The occurrence of lights that changed were randomized within each drive. In accord with positive guidance principles (see, e.g., Alexander \& Lunfield, 1986), the rectagular and diamond sign icons were displayed for 4 seconds in the HUD format $12 \mathrm{~s}$ to $8 \mathrm{~s}$ in advance of the intersection (see Figure 1, right panel).

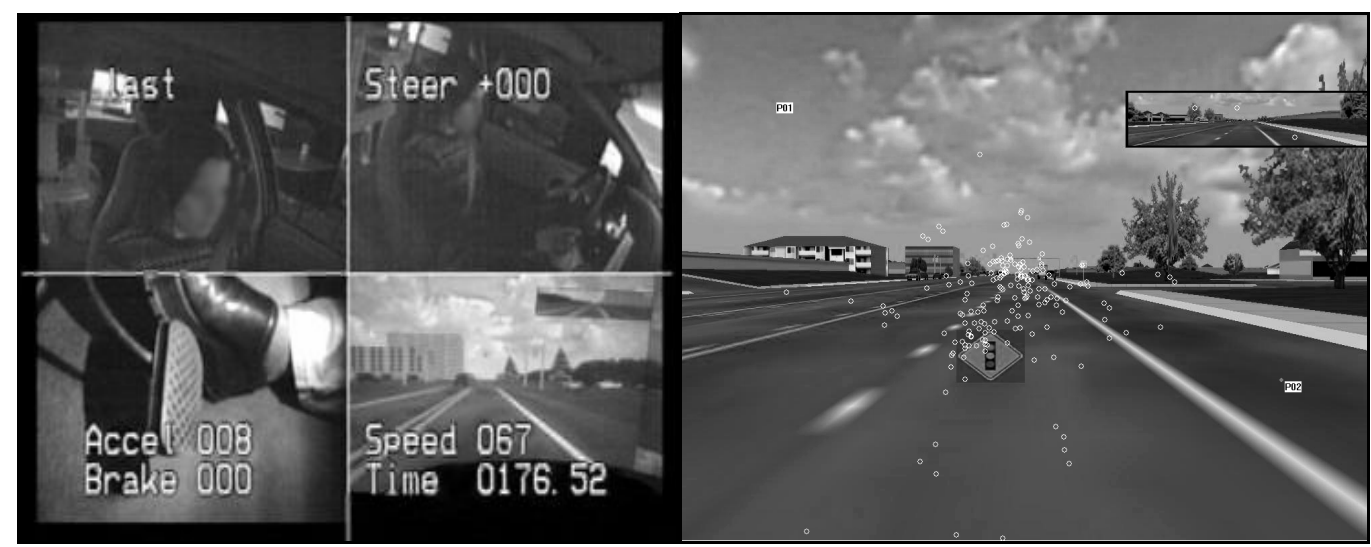

Figure 1. The image on the left shows a screen capture of the interior of the simulator with brake, accelerator, speed and steering variables overlaid. The image on the right illustrates the diamond in-vehicle sign with the corresponding area of interest (AOI) surrounding it. Fixations for the 4 seconds that the HUD was on prior to the intersection are shown as white dots. 


\section{RESULTS}

A modified UNIANOVA (SPSS v. 11.5) was used to analyze the experimental design for each dependent variable. The independent variables were age group (18-24, 65+), drive type (baseline and experimental), and head-up display sign type (diamond and rectangular signs). Dependent variables collected included stop or go behaviour, vertical and horizontal gaze variability, fixation duration percent, and fixation count.

\section{Stop/Go Probability}

Significantly fewer drivers ran the amber light in the in-vehicle advanced sign (HUD) conditions than in the baseline condition $\left(\chi^{2}(1,576)=16.5, p<0.0001\right)$. The percentage of those stopping and going differed between age groups in the baseline $\left(\chi^{2}(1,288)=4.4, p<0.037\right)$ and HUD $\left(\chi^{2}(1,288)=11.8, p<0.001\right)$ conditions (see Figure 2$)$. Older drivers were less likely to stop and more likely to go during the baseline condition. The net effect of the HUD signs was to increase the percentage of those stopping in both age groups.

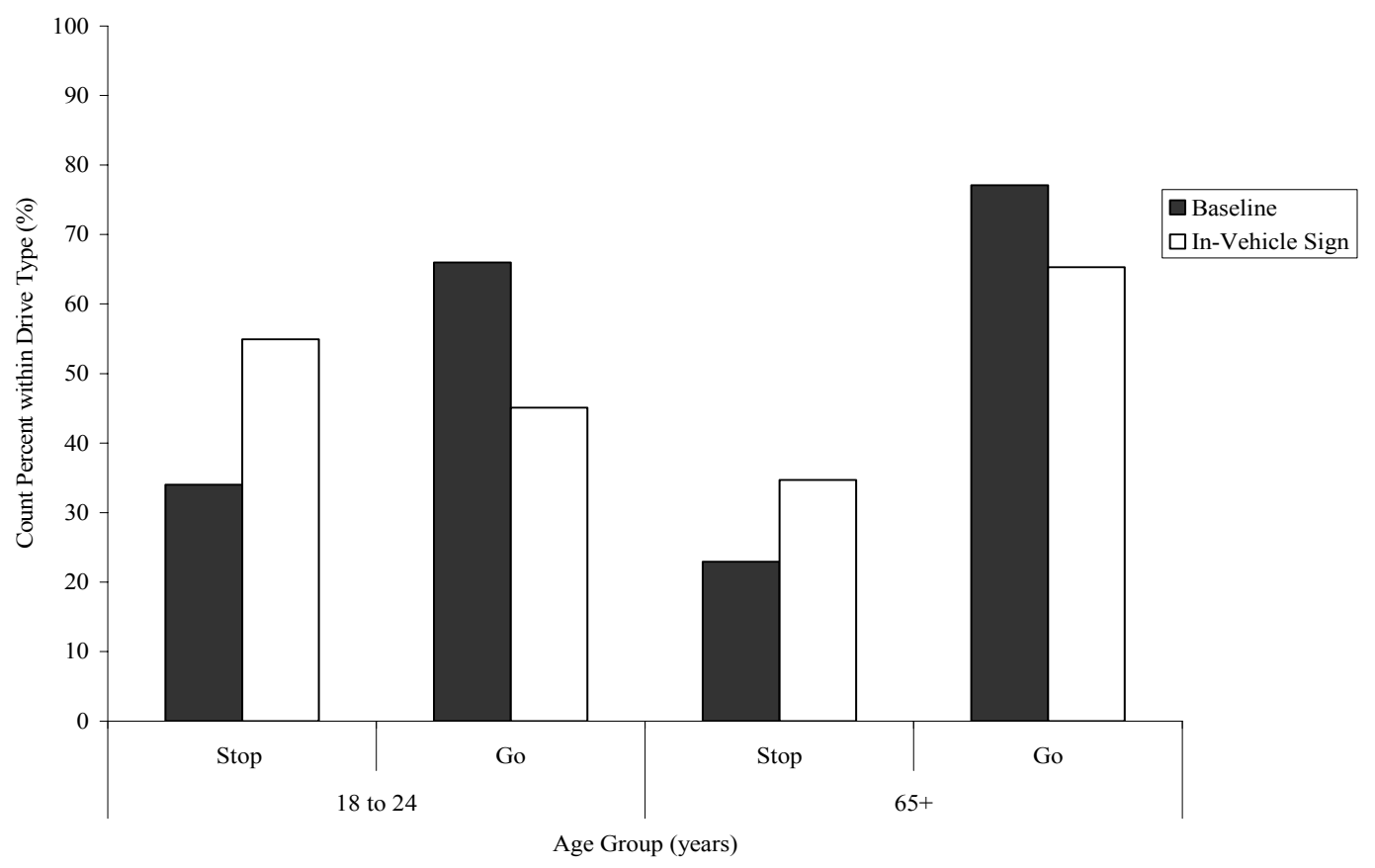

Figure 2. Percentage of those stopping and going by age group and baseline and in-vehicle sign conditions

\section{Eye Movement Analysis}

Eye movement data was analyzed for the duration of the advanced warning sign presentation, starting 12 seconds prior to the intersections for a duration of four seconds. Overall fixation was analyzed, as well as fixations with the advanced warning heads up display (HUD) as the area of interest (AOI). 
Gaze variability. Gaze variability was calculated as the standard deviation in participant's vertical and horizontal eye positions during each presentation of the HUD sign (cf., Recarte \& Nunes, 2000).

Vertical variability. Younger drivers had significantly greater vertical gaze variability $(M=$ $23.29, S E=0.47)$ than those in the older age group $(M=19.90, S E=0.54), F(1,322)=22.60, p$ $<0.001$. In the baseline condition, drivers had significantly greater variability in vertical gaze position $(M=23.10, S E=0.49)$ compared to the experimental condition with the HUD $(M=$ 20.38, $S E=0.51), F(1,322)=4.18, p=0.05$.

Horizontal variability. Older drivers exhibited significantly greater horizontal variability $(M=$ $24.92, S E=.80)$ compared to the younger drivers $(M=19.04, S E=.67), F(1,322)=31.71, p<$ 0.001 . In the baseline drive, a significantly higher horizontal gaze variability was found $(M=$ 23.61, $S E=0.65)$ compared to the experimental HUD drive $(M=20.03, S E=0.80), F(1,322)=$ $10.47, p<0.05$. It is of interest that older drivers' horizontal gaze variability was significantly greater in the baseline intersections $(M=27.62)$ than in the experimental HUD intersections $(M$ $=22.22$ ), whereas the younger drivers did not exhibit such a difference in eye behaviour; baseline $(M=19.96)$, experimental $(M=18.2)$.

Fixation duration percent. Analysis of the HUD fixation duration percent revealed that younger drivers spent a significantly large percent of their time fixating on the HUD $(M=27.73, S E=$ $2.00)$ compared to the older drivers $(M=15.49, S E=2.35), F(1,122)=15.74, p<0.001$.

Fixation count. Overall fixation counts showed that the older drivers made a significantly larger number of fixations to the roadway scene $(M=10.23, S E=0.17)$ compared to the younger drivers $(M=9.36, S E=0.14), F(1,298)=15.86, p<0.001$. But when the HUD sign was presented, it was found that younger drivers made significantly more fixations to the HUD itself $(M=2.97, S E=0.22)$ compared to the older drivers $(M=1.83, S E=0.26), F(1,122)=10.94, p$ $=0.001$.

\section{DISCUSSION}

In-vehicle signs increased both younger and older drivers' stopping at intersections with relatively short yellow light onsets. In the baseline drives, older drivers were less likely to stop and more likely to go than younger drivers. Presentation of the HUD in advance of the intersection allowed drivers to decrease their velocity and thus, they were more likely to be able to come to a stop when a late yellow light appeared.

Eye movement analysis revealed that younger drivers tended to focus on the HUD more often and for longer periods of time than the older drivers. Several plausible explainations are possible for these results. First, older drivers may not have fixated as often or for as long on the HUD because they may have been less comfortable restricting their search for important traffic information ahead. Visual search for signs and vehicles at intersections can be problematic for older drivers for a number of reasons (Caird, et al., in press; Ho et al., 2001; Maltz \& Shinar, 1999). Second, younger drivers may have been more curious about the HUD presence, and thus looked at it more often (see, e.g., Kiefer, 1991). Looking at the HUD may decrease with longer 
exposure to it, but determination of these longer-term effects will require a different research approach.

Recarte and Nunes (2000) used horizontal and vertical gaze variability as measures of attentional demand while performing secondary tasks. Decreases in gaze in either plane were attributed to increased demand. In this study, when the HUD was present, gaze variability decreased in both the horizontal and vertical planes. The advanced HUD sign may decrease the requirement to look at the traffic lights as frequently. However, reductions in horizontal scanning may indicate a carryover from looking at the HUD, which is not necessarily a positive benefit.

\section{ACKNOWLEDGMENTS}

The research project described in this paper was performed under contract with the Transportation Development Centre of Transport Canada and funded by Transport Canada. (C) 2005 Government of Canada (Transportation Development Centre of Transport Canada). All rights reserved. This paper reflects the views of the authors and not necessarily those of Transport Canada. Tak Fung graciously assisted with the analysis of the experimental designs and Mike Boyle provided programming assistance for networking, data extraction tools, and real time calibration. Andrew Mayer assisted with data analysis. Funding by the AUTO21 National Centres of Excellence to the second author enhanced the scope of the analyses that were performed. The Canada Foundation for Innovation and Alberta Innovation and Science provided support for the hardware, software, and infrastructure of the University of Calgary Driving Simulator (UCDS).

\section{REFERENCES}

Alexander, G.J., \& Lunenfeld, H. (1986). Driver expectancy in highway design and traffic operations. Washington, DC: Federal Highway Administration.

Caird, J.K. (2004). Intelligent transportation systems (ITS) and older drivers' safety and mobility. Transportation in an aging society: A decade of experience, 236-255. Washington, D.C.: National Academy of Sciences, Transportation Research Board.

Caird, J.K., Chisholm, S., Lockhart, J., Vacha, N., Creaser, J.I., Edwards, C., \& Hatch, K. (2005). In-vehicle intelligent transportation system (ITS) countermeasures to improve older driver intersection performance. Transportation Development Centre, Transport Canada.

Caird, J. K., \& Chugh, J. (1997). Time cost of heads-up displays for older drivers: Timing of critical event onset, task type, and display location. Proceedings of the 41st Annual Human Factors and Ergonomics Society Meeting, pp. 1008-1012. Santa Monica, CA: Human Factors and Ergonomics Society.

Caird, J.K., Edwards, C.J., Creaser, J.I., \& Horrey, W.J. (in press). Older driver failures of attention at intersections: Using change blindness methods to assess turn decision accuracy. Human Factors.

Chang, M.-S., Messer, C.J., \& Santiago, A.J. (1985). Timing traffic signal change intervals based on driver behavior. Transportation Research Record, 1027: 20-30.

Hanowski, R. J., Dingus, T. A., Gallagher, J. P., Kieliszewski, C. A., \& Neale, V. L. (1999). Driver response to in-vehicle warnings. Transportation Human Factors, 1(1): 91-106. 
Ho, G., Scialfa, C. T., Caird, J. K., \& Graw, T. (2001). Traffic sign conspicuity: The effects of clutter, luminance, and age. Human Factors, 43(2): 194-207.

Kiefer, R. (1991). Effect of a head-up versus head-down digital speedomoter on visual sampling behavior and speed control performing during daytime automobile driving. SAE Technical Paper No. 910111. New York: Society of Automotive Engineers.

Maltz, M., \& Shinar, D. (1999). Eye movements of younger and older drivers. Human Factors, 41(1): 15-25.

Nakata, A., Campbell, J.L., \& Richman, J.B. (2002). Driver acceptance of general vs. specific icons for in-vehicle information. Proceedings of the Human Factors and Ergonomics Society $46^{\text {th }}$ Annual Meeting (CD-ROM). Santa Monica, CA: HFES.

Preusser, D.F., Williams, A.F., Ferguson, S.A., Ulmer, R.G., \& Weinstein, H.B. (1998). Fatal crash risk of older drivers at intersections. Accident Analysis and Prevention, 30(2): 151-159.

Regan, M.A. (2004). A sign of the future I \& II: Intelligent transport systems \& human factors. In: C. Castro \& T. Horberry (Eds.), The human factors of transport signs, 213-238. Boca Raton, FL: CRC Press.

Recarte, M.A. \& Nunez, L.M. (2000). Mental workload while driving: Effects on visual search, discrimination, and decision making. Journal of Experimental Psychology: Applied, 9(2): 119-137.

Transport Canada. (2002). 2002 Annual Report. Road Safety Vision 2010. [Online] http://www.tc.gc.ca/roadsafety/vision/2002/pdf/rsv2002s.pdf

Tufano, D.R. (1997). Automotive HUDs: The overlooked safety issues. Human Factors, 39(2): 303-311.

Wolffsohn, J. S., McBrien, N. A., Edgar G. K., \& Stout, T. (1998). The influence of cognition and age on accommodation, detection rate and response times when using a car head-up display (HUD). Ophthalmic Physiology \& Optometry, 18(3): 243-253. 